\title{
Glukosinolatlardan Hidrolize Edilen Sülforafanın Potansiyel Etkileri ve Nrf2-Keap-1 Sinyal Yolağı ile İlişkisi
}

\author{
Deniz KARAKÇI \\ Tekirdă̆ Namık Kemal Üniversitesi Veteriner Fakültesi Biyokimya Anabilim Dalı Tekirdăg, Türkiye
}

Atıf yapmak için: Karakçı, D. (2021). Glukosinolatlardan Hidrolize Edilen Sülforafanın Potansiyel Etkileri ve Nrf2-Keap-1 Sinyal Yolağı Ile Ilişkisi. Anadolu Çev. ve Hay. Dergisi, 6(3), 352-356.

How to cite: : Karakç, D. (2021). The potential effects of sulforaphane hydrolyzed from glucosinolates and relationship between Nrf-2 Keap-1 signal pathway. J. Anatolian Env. and Anim. Sciences, 6(3), 352-356.

: https://orcid.org/0000-0002-1884-1874

\section{*Sorumlu yazarm:} Deniz KARAKÇI

Tekirdağ Namık Kemal Üniversitesi, Veteriner Fakültesi, Biyokimya Anabilim Dalı Tekirdağ, Türkiye 凶: dkarakci@nku.edu.tr
Öz: Glukosinolatlar (Gls), brassica sebzelerinde bulunan ekonomik açıdan önemli olan ikincil bitki metabolitleridir. Glukosinolatlar ve bunların hidroliz ürünleri insanlar ve hayvanlar üzerinde birçok faydalı etkiye sahiptir. Gls, bitki içeriğinde ve bağırsak mikroflorasında bulunan mirosinaz enzimi ile hidrolize edilir ve bu şekilde biyolojik aktiviteleri ortaya çıkarabilmektedir. Glukosinolatların parçalanma ürünlerinden biri olan izotiyosiyanatlar bazı kanser türlerinin önlenmesinde önemli roller oynamaktadır. En çok incelenen izotiyosiyanat öncül maddesi sülforafan, memeli hücre koruyucu enzimlerinin güçlü bir uyarıcısı olarak brokoli özlerinden izole edilmektedir. Sülforafanın, bir sıçan memeli tümör modelinde, tümörlerin boyutunu indirekt bir antioksidan olarak çalışarak küçülttüğü bildirilmiştir. Nükleer faktör eritroid 2 ile ilişkili faktör 2 (Nrf2), antioksidan ve detoksifiye eden genlerin ekspresyonunu düzenleyen, spesifik bir gen tarafindan kodlanan bir transkripsiyon faktörüdür. Nrf2, birçok Faz I ve Faz II ilaç metabolize edici enzimlerin ekspresyonunu kontrol etmektedir. Aynı zamanda, Kelch-benzeri ECH birleştirici protein 1 (Keap1) sistein aminoasitlerce zengindir ve oksidatif stresin oluşmasına bağlı olarak çalışabilen bir sensör görevi yapmaktadır. Hücre koruyucu proteinleri kodlayan genlerin çoğu, Keap1-Nrf2-ARE antioksidan yanit elementi 'ARE' sinyal yolu boyunca ortak transkripsiyonel düzenlemeyi sağlamaktadır. Artan strese göre, Keap1 Nrf2'yi aktive eder ve ARE'yi uyarmaktadır. Özellikle glukosinolatlardan hidrolize edilen sülforafan, bu yolu kullanarak oksidatif hasara ve çeşitli kanser türlerine karş1 vücudu koruduğu düşünülmektedir.

$\underline{\text { Anahtar kelimeler: Glukosinolatlar, kanser, oksidatif stres, sülforafan. }}$

\section{The potential effects of sulforaphane hydrolyzed from glucosinolates and relationship between Nrf-2 Keap-1 signal pathway}

*Corresponding author's: Deniz KARAKÇI

Tekirdag Namık Kemal University Faculty of Veterinary Medicine Department of Biochemistry Tekirdağ, Turkey 凶:dkarakci@nku.edu.tr

\begin{abstract}
The glucosinolates (Gls) are economically important secondary plant metabolites which occur in all of brassica vegetables. Glucosinolates and their hydrolysis products have many beneficial effects on humans and animals. Gls are hydrolyzed by myrosinase enzyme found in plant or produced in intestinal microflora, in this way it can appear their biological activities. One of breakdown products of Gls called isothiocyanates and they have an essential role in prevention some cancer types. The most studies on isothiocyanate, sulforaphane (SFN) was isolated from extracts of broccoli as a potent inducer of mammalian cytoprotective enzymes. It is reported that sulforaphane reduced the size of tumors in a rat mammary tumor model by acting as an indirect antioxidant. NF-E2-related factor 2 (Nrf2) is a transcription factor encoded by a specific gene that regulates the expression of antioxidant and detoxifying genes. Nrf2 controls the expression of many Phase I and Phase II drug-metabolizing enzymes. Also, Kelch-like ECH associating protein 1 (Keap 1) is rich from amino acid cysteine and acts as a sensor that can work according to the existance of oxidative stress. Many of the genes encoding cytoprotective proteins share common transcriptional regulation through the Keap1-Nrf2-ARE pathway. According to increasing stress, Keap1 activates Nrf2 and induce the Antioxidant Response Element (ARE). Especially sulforaphane that is hydrolyzed from glucosinolates protects the body against oxidative damage and several cancer types by using this pathway.
\end{abstract}

Keywords: Cancer, glucosinolates, oxidative stress, sulforaphane. 


\section{GİRIŞ}

Glukosinolatlar (Gls), Brassicaceae ailesinin ekonomik olarak öneme sahip, sülfür içeren ikincil bitki metabolitleridir. 120'den fazla farklı glukosinolat çeşidi yan-zincir yapısının değişikliğe uğramasıyla elde edilmektedir (Belenli vd., 2016; Chen vd., 2001). Glukosinolatların genel kimyasal yapısı, $\beta$-D-tiyoglukoz grubu, bir sülfonlanmış oksim parçası ve metiyonin, triptofan veya fenilalaninden türetilen değişken bir yan zincirden oluşur (Tripathi vd., 2007).

1970'lerden beri glukosinolatlar ve bunların hidroliz ürünlerinin, insan ve hayvan beslenmesi üzerine faydalı ve biyolojik etkileri üzerine çalışmalar yapılmaktadır. Ayrıca Brassica sebzelerinin karakteristik tat ve lezzetinden kısmen sorumlu oldukları bulunmuştur. Brassicaceae ailesi, brokoli, brüksel lahanası, lahana, yeşil lahana, karnabahar, şalgam ve tere gibi sebzeleri içermektedir. $\mathrm{Bu}$ sebzeler dünya çapında yaygın olarak yetiştirilmekte ve tüketilmektedir. $\mathrm{Bu}$ sebzeler içerisinde yer alan brokoli, ayrı bir öneme sahiptir ve brokolinin düzenli tüketimi ile bazı kanser türlerini önlemedeki etkileri birçok bilimsel çalışmada araştırılmıştır (Belenli \& Polat, 2018; Cartea, 2008). Glukosinolatlar, bitkinin tüm kısımlarında bulunur ve fiziksel olarak mirosinaz (tiyoglukozit glukohidrolaz, EC 3.2.3.1) enzimi ile hidroliz ürünlerine ayrılır. Bitkiye 1sıl işlem uygulanması veya vücuda alındıktan sonra sindirim sırasında bitki dokularının zarar görmesi ile mirosinaz enzimi aktive olur böylece glukosinolat ve biyolojik etkilere sahip hidroliz ürünlerinin açığa çıkması sağlanmış olur (Tripathi vd., 2007). Glukosinolatlar, hem bitkide bulunan hem de bağırsak mikroflorası tarafindan üretilen mirosinaz enzimi tarafından hidrolize edilir ve parçalanma ürünleri serbest hale geçer (Bernardi vd., 2003; Cheng vd., 2004; Fenwick vd., 1983; Finiguerra vd., 2001; Mithen, 2001).

Glukosinolatların (Gls) hidroliz ürünleri, birçok hastalığa karşı koruma ve savunma sağlayan biyolojik aktivitelere sahiptir (Halkier vd., 1997). Hidroliz ürünleri şeker içermeyen bir aglikon bölümü, glikoz ve sülfattan oluşur. Aglikon kısmı kararsızdır ve Gls'in yapısına bağlı olarak izotiyosiyanatlar (ITC), tiyosiyanatlar, nitriller, oksazolidin tiyonlar ve epitionitriller gibi hidroliz ürünlerinden oluşmaktadır. Glukosinolatların biyolojik aktivitelerinin neredeyse tamamı, parçalanma ürünleri, özellikle izotiyosiyanatlar tarafindan gerçekleştirildiği bildirilmiştir (Vig vd., 2009).

İotiyosiyanatlardan İole Edilen Sülforafanın Biyolojik Etkileri: Paul Talalay vd., (2003) tarafindan izotiyosiyanatlarla ilgili kabul gören ilk çalışmalar, faz I enzimlerinin inhibe edilmesi ve sitoprotektif (hücre koruyucu) faz II enzimlerinin transkripsiyonunu indükleyerek, DNA'yı mutasyona uğratacak olan mevcut kanserojenlerin seviyesinin azaltılması yönünde olmuştur.
Yapılan ilk çalışmalarla elde edilen bu keşif, murin Hepalc1c7 hücrelerindeki NAD(P)H:-kinon oksidoredüktaz-1'in (NQO1) artan transkripsiyonuna dayanan indüksiyon yeteneklerini taramak için kantitatif bir biyoanalizin geliştirilmesine işaret etmiştir. En çok çalışma yapılan izotiyosiyanatlardan biri olan sülforafan, brokoli ekstraktlarından, memelilerdeki sitoprotektif enzimlerin güçlü bir indükleyicisi olarak izole edilmiştir. Sülforafan, brokolinin ekstraksiyonu sonucu izole edilen, temel aktif bileşiğidir (Dinkova-Kostova vd., 2012).

İzotiyosiyanatlardan elde edilen sülforafanın çeşitli memeli patojenlerine karşı aktivitesi (örneğin Escherichia coli, Salmonella typhimurium, Candida sp.) yüzyıllardır yaraların tedavisinde kullanılmakta ve antitümör ajanlar olarak biyolojik özellikler göstermektedir (Fahey vd., 2001). Memeli dokuları mirosinaz enzimi içermemesine rağmen, memelilerde glukosinolatların izotiyosiyanatlara dönüşümü, gastrointestinal sistemin bakteriyel mikroflorasında bulunan mirosinaz ile gerçekleşmektedir (Dinkova- Kostova vd., 2012). Gönüllü insanlarda, sülforafan ve izotiyosiyanatın, bitkisel kaynağının sindirim sonrası metabolizması incelenmiş ve her iki çalışmada da, glukosinolatlardan izotiyosiyanatların hidrolizinde sindirim sistemindeki mikrofloranın önemli rolü olduğu görülmüştür (Shapiro vd., 2001).

Bitki ekstraktlarından izotiyosiyanatların eldesi, genel olarak yüksek performanslı sıvı kromotografisi (HPLC) kullanılarak gerçekleşmektedir (Zhang vd., 1992; Kore vd., 1993). Günümüzde, HPLC için bu tekniğin modifikasyonu ile bitki ekstraktları gibi kompleks biyolojik sıvılarda 10 pmol'den az izotiyosiyanat ölçülebilmektedir (Zhang vd., 1996). Glukosinolatlardan ekstrakte edilen izotiyosiyanatlarda, saflaştırılmış mirosinaz enzimi ölçümü, belirlenen toplam glukosinolat titresi ve iyon çifti kromatografisi teknikleriyle doğrudan ölçülen glukosinolat seviyeleri arasında mükemmel bir korelasyon bulunmaktadır (Fahey vd., 1999).

Son yıllarda, birçok kanser türünün görülme sıklığını azaltmak için meyve ve sebzelerinden yararlanılmaktadır. Özellikle turpgil (Brassica) sebzelerinin tüketiminin artmasıyla bu konudaki çalışmalar kanıt niteliği kazanmaktadır (Doll, 1992; Fahey \& Talalay 1999; Michaud vd., 1999; Steinmetz \& Potter 1991; Verhoeven vd., 1996). Bu sebzelerin kanser kemoprotektif aktivitesinin en azından bir bölümünün glukosinolat içermelerinden kaynaklandığına inanılmaktadır (Fahey vd., 2001). Bu sebzelerin en önemli özelliği, Faz II enzimlerinin indükleyicileri olarak, apoptozu uyarır aynı zamanda redoks regülatörü olarak görev yapar ve Faz I enzimlerini inhibe ederek, metabolitlerin kanser önleyici olmasını sağlar. Sülforafan, sıçan meme tümörü modelinde (Fahey vd., 1997; Zhang vd., 1994), indirekt antioksidan 
etki gösterir (Fahey \& Talalay, 1999). Bunun yanında kolon kanseri hücrelerinde in vitro olarak seçici sitotoksik etki yapıp (Gamet-Payrastre vd., 1998), sitokrom p450'yi inhibe ederek memeli hücrelerindeki tümörün insidensinde ve büyüklügünnde azalmalar sağlamaktadır (Maheao vd., 1997; Morel vd., 1997). Ayrica, in vitro olarak insan kolon kanseri hücrelerinde, hücre siklusunu durdurarak apoptozu indüklemektedir (Gamet-Payrastre vd., 2000). İzotiyosiyanatların, sıçan ve fare tümör modellerinde, akciğer ve yemek borusu kanserinin uyarılmasını da inhibe ettiği tespit edilmiştir. $\mathrm{Bu}$ etkiler, sitokrom p450 mekanizmasının da kuvvetli bir şekilde inhibe edildiğini göstermektedir (Fahey vd., 1997).

\section{Nrf2-Keap-1 Sinyal Yolağı ve Kanser} Arasındaki İlişki: Nükleer faktör eritroid-2 ile ilişkili faktör 2 (Nrf2), oksidatif strese direnç gösteren ve çeşitli çevresel stres öncülerine karşı uyumlayıcı bir yanıtı gerçekleştirebilen bir transkripsiyon faktörüdür. Kelchbenzeri ECH ile ilişkili protein (Keap 1) ile Nrf2 ilişkisi, kansere neden olan somatik mutasyonların biyolojik önemini göstermektedir (Hayes \& Dinkova-Kostova, 2014). Keap1, 624 amino asit içerisinde, 25 sistein kalıntısı bulunan, çinko metalloprotein grubuna ait uyarıcı bir sensördür. Keap1'in sistein açısından zengin olması, oksidatif stresin varlığına göre hareket edebilme özelliği kazanmasını sağlamaktadır. Hücresel strese karşı savunma mekanizmalarının ana düzenleyicisi olarak kabul edilen Nrf2/Keap1 sinyal yolağı, hasarlı makro moleküllerin onarımında veya ortadan kaldırılmasında görev alan çeşitli hücre koruyucu protein ağlarına ait gen ekspresyonlarını düzenleyerek, hücrenin stres koşullarında hayatta kalmasını sağlamaktadır. Hücre koruyucu proteinleri kodlayan genlerin çoğu, Keap1-Nrf2 ve antioksidan yanıt elementi 'ARE' yolağı aracıllı̆ı̆yla transkripsiyonel regülasyonda ortak rol oynamaktadırlar (Dinkova-Kostova \& Kostov, 2012). Nrf2, sitoplazmada Keapl'e bağlıdır. Reaktif oksijen türleri (ROS), endojen antioksidan kapasitenin üstesinden geldiğinde Keap-1, Nrf2'yi serbest bırakır ve bu daha sonra, diğer transkripsiyon faktörleri ve ARE'nin de yardımıyla Nfr2 çekirdeğe geçer. Bu olay, glutatyon (GSH) sentezinden sorumlu olan başlıca anahtar antioksidanların ve sitoprotektif proteinlerin ve enzimlerin transkripsiyonel aktivasyonuna neden olur (Kavian vd., 2018).

İzotiyosiyanatlar, Keap1 spesifik sistein kalıntıları ile reaksiyona girer ve ubiqutinasyon ve degradasyon gerçekleştirmek için Nrf2'yi hedefleme kabiliyetini ortadan kaldırırlar. Sitozolde Nrf2'nin ubiqutinasyonunun ve proteozomal degredasyonunun önlenmesiyle Nrf2'nin nükleusa translokasyonu sağlamış olur (Mitsuishi vd., 2012). İnsan ve fare dokularında in vivo olarak Nrf2 transkripsiyon faktörü, ilaç metabolize eden enzimleri kontrol ederek, ekspresyona uğramaktadır. Nrf2-
Keap1 sinyal yolunun, oksidatif strese hücresel yanıtta önemli rollere sahip olduğu tespit edilmiştir. Nrf2'nin aktivasyon mekanizması kapsamlı bir şekilde çalışmaları devam etmektedir (Dinkova-Kostova vd., 2005). Normal koşullar altında, Nrf2 sitoplazmaya yerleşir ve burada aktin bağlayıcı protein, Keap1, Nrf2 ile etkileşime girer ve onu aktive eder. Stresin arttığı durumlarda, Keap1 daha sonra hücre çekirdeğine göç eden ve ARE'yi azaltmak için DNA'ya bağlanan Nrf2'yi aktive eder ARE daha sonra çeşitli güçlü antioksidan enzimleri ve detoksifiye edici proteinlerin tekrar düzenlenmesini gerçekleştirir (Kobayashi \& Yamamoto, 2005). Nrf2 hedef genlerinin promotor bölgesindeki ARE dizisine özgü bir şekilde bağlanır ve ilaç detoksifikasyonu, antioksidan cevap, NADPH rejenerasyonu ve metabolizmanın düzenlenmesinde rol oynayan genlerden protein kodlanmasını sağlar. Nrf2 hedef genleri, geniş bir antioksidan enzimler ağı, ksenobiyotik detoksifikasyonunda yer alan proteinler, hasarlı proteinlerin onarımı ve uzaklaştırılması, enflamasyonun inhibisyonu ve diğer transkripsiyon faktörlerinden oluşur (Yang vd., 2016). Son yllarda, sitoprotektif gen ekspresyonunun düzenleyicisi rolünün bir parçası olarak, Nrf2'nin mitokondriyal işlevi etkilediği ortaya çıkmıştır. Artan Nrf2 aktivitesi, mitokondriyal toksinlere karş1 koruma sağlar (Holmström vd., 2016). Paul Talalay vd. (2003) fare dokularında Nrf2'nin, Faz I ve Faz II ilaç metabolize eden enzimlerin ekspresyonunda rol oynadığını göstermiştir. Masayuki Yamamoto vd. ise Nrf2 negatif farelerde, GST (Glutatyon peroksidaz) ve NQO1'i uyardığını tespit etmiştir (Belenli \& Polat, 2017; DinkovaKostova \& Kostov, 2012).

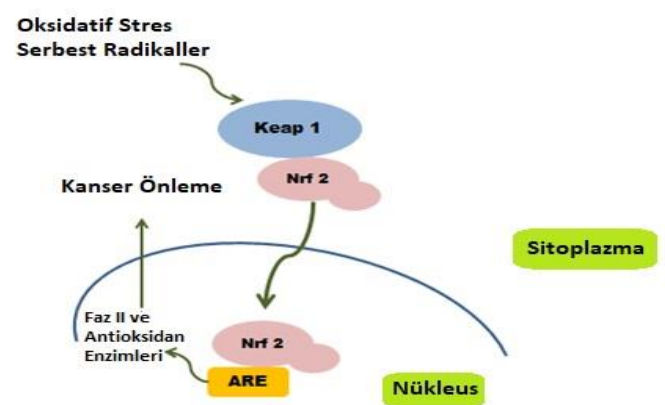

Sekil 1. Nf2-Keap 1-ARE Sinyal Yolağ1. Figure 1. Nf2-Keap 1-ARE Signal Pathway.

Keap1, Nrf2'nin başlıca baskılayıcısıdır ve bu durum farelerde Keapl'in miktarının azalmasının gözlenmesi ile desteklenmektedir. Keap1'in, Nfr2 transkripsiyon faktörünün miktarını ve aktivitesini arttırmak için yeterlidir. Ayrıca, Keap1'deki somatik mutasyonlar, akciğer, meme ve kolon kanseri olan bazı hastalarda Keap1 promotörünün hipermetilasyonu şeklinde tümörlerdeki Nrf2'nin up-regülasyonuna neden olmaktadır (Hayes \& Dinkova-Kostova, 2014). 


\section{SONUÇ}

Özellikle glukosinolatların hidroliz ürünü olan sülforafanın kimyasal karsinojenlere karşı kemoprotektif özellikleri kanıtlanmıştır. Nrf2, sitoplazmada Keap1'e bağlıdır. Sülforafan tüketimi ile uyarılan Keap-1 harekete geçer ve Nrf2'yi serbest bırakır. Daha sonra, Nfr2 çekirdeğe geçer ve böylece Faz II enzimlerinin ekspresyonu sağlanmış olur. Faz II enzimlerinin ekspresyonu ile Nrf2-Keap-1-ARE sinyal yolunu indüklenerek antioksidan etkilerinin gösterilmesini sağlanır ve oksidatif hasara karşı koruma ve birçok kanser türünü önleme gerçekleşmiş olur. $\mathrm{Bu}$ derlemede, sülforafan dâhil olmak üzere düzenli olarak brassica sebzeleri ve özellikle brokoli tüketiminin bazı hastalıkların zararlı etkilerini azalttığı kanısına varılmıştır.

Glukosinolatların ve hidroliz ürünlerinin detaylı etkilerini incelemek için daha fazla araştırmaya ihtiyaç duyulmaktadir.

\section{KAYNAKLAR}

Belenli, D., Polat, Ü., Berhow, M.A., Orman, A. \& Yeşilbağ, D. (2016). Effects of glucosinolates and their hydrolysis products on biochemical and performance parameters in broiler chicken diets. Indian Journal of Animal Sciences, 86(10), 72-78.

Belenli, D. \& Polat, Ü. (2017). Sulforaphane acts as a cancer fighter. 8 th Balkan Animal Science Conference Balnimalcon 2017, 6-8 Eylül 2017, Prizren, Kosovo p.126.

Belenli, D. \& Polat, Ü. (2018). Effects of dietary cress seed (Lepidium sativum) supplementation on biochemical, performance parameters and MDA levels in broilers. 1st International Veterinary Biochemistry and Clinical Biochemistry Congress, 12-15 Nisan 2018, Hatay, Turkey. p.196.

Bernardi, R.L., Finiguerra, M.G., Rossi, A.A. \& Palmieri, S. (2003). Isolation and biochemical characterization of a basic myrosinase from ripe crambe abyssinica seeds, highly specific for epiprogoitrin. Journal of Agricultural and Food Chemistry, 51(9), 2737-44. DOI: 10.1021/jf020796g

Chen, S. \& Andreasson, E. (2001). Update of glucosinolate metabolism and transport. Plant Physiology and Biochemistry, 39, 743-758. DOI: 10.1016/S0981-9428(01)01301-8

Chen, Y.Z., Lin, L., Wang, C.W., Yeh C.C. \& Hwang, S.Y. (2004). Response of two pieris (Lepidoptera: Pieridae) species to fertilization of a host plant. Zoological Studies, 43(4), 778-786.

Cheng, D.L., Hashimoto, K. \& Uda, Y. (2004). In vitro digestion of sinigrin and glucotropaeolin by single strains of Bifido-bacteriumand identification of the digestive products. Food
Chemical Toxicology, 42, 351-357. DOI: 10.1016/j.fct.2003.09.008

Cartea, M.E. \& Velasco, P. (2008). Glucosinolates in Brassica foods:bioavailability in food and significance for human health. Phytochemistry Reviews, 7, 213-229. DOI: 10.1007/s11101-0079072-2

Dinkova-Kostova, A.T., Holtzclaw, W.D. \& Wakabayashi, N. (2005). Keap1, the sensor for electrophiles and oxidants that regulates the phase 2 response, is a zinc metalloprotein. Biochemistry, 44, 6889-6899. DOI: $10.1021 / \mathrm{bi047434h}$

Dinkova-Kostova, A.T. \& Kostov, R.V. (2012). Glucosinolates and isothiocyanates in health and disease. Trends in Molecular Medicine, 18(6), 337-347. DOI: 10.1016/j.molmed.2012.04.003

Doll, R. (1992). The lessons of life: keynote address to the nutrition and cancer conference. Cancer Research, 52, 2024-2029.

Fahey, J.W., Zhang, Y. \& Talalay, P. (1997). Broccoli sprouts: an exceptionally rich source of inducers of enzymes that protect against chemical carcinogens. Proceedings of the National Academy of Sciences USA, 94, 10367-10372. DOI: 10.1073/pnas.94.19.10367

Fahey, J.W. \& Talalay, P. (1999). Antioxidant functions of sulforaphane: a potent inducer of Phase 2 detoxication enzymes. Food Chemical Toxicology, 37, 973-979. DOI: 10.1016/s02786915(99)00082-4

Fahey, W.J., Amy, T., Zalcmann, L. \& Talalay, P. (2001). The chemical diversity and distribution of glucosinolates and isothiocyanates among plants. Phytochemistry, 56, 5-51. DOI: 10.1016/s00319422(00)00316-2

Fenwick, G.R., Heaney, R.K. \& Mullin, W.J. (1983). Glucosinolates and their breakdown products in food and food plants. Critical Reviews in Food Science and Nutrition, 18, 123-201. DOI: 10.1080/10408398209527361

Finiguerra, M.G., Iori, R. \& Palmieri, S. (2001). Soluble and total myrosinase activity in defatted Crambe abyssinica meal. Journal of Agricultural and Food Chemistry, 49(2), 840-845. DOI: 10.1021/jf000917h

Gamet-Payrastre, L., Lumeau, S., Gasc, N., Cassar, G., Rollin, P. \& Tulliez, J. (1998). Selective cytostatic and cytotoxic effects of glucosinolates hydrolysis products on human colon cancer cells in vitro. Anticancer Drug, 9, 141-148. DOI: 10.1097/00001813-199802000-00005

Gamet-Payrastre, L., Li, P., Lumeau, S., Cassar, G., Dupont, M.A., Chevolleau, S., Gasc, N., Tulliez, J. \& Tercé, F. (2000). Sulforaphane, a naturally occurring isothiocyanate, induces cell cycle arrest and apoptosis in HT29 human colon cancer cells. Cancer Research, 60, 1426-1433.

Halkier, B.A. \& Du, L.C. (1997). The biosynthesis of glucosinolates. Trends in Plant Science, 2, 425431. DOI: 10.1016/S13601385(97)9006-1 
Hayes, J.D. \& Dinkova-Kostova, A.T. (2014). The Nrf2 regulatory network provides an interface between redox and intermediary metabolism. Trends in Biochemical Sciences, 39(4), 199-217. DOI: 10.1016/j.tibs.2014.02.002

Holmström, K.M., Kostov, R.V. \& Dinkova-Kostova, A.T. (2016). The multifaceted role of $\mathrm{Nrf} 2$ in mitochondrial function. Current Opinion in Toxicology, 1, 80-91. DOI: 0.1016/j.cotox. 2016.10.002

Kavian, N., Mehlal, S., Jeljeli, M., Saidu,N.E.B., Nicco, C., Olivier, C., Chouzenoux, S., Cauvet, A., Camus, C., Ait-Djoudi, M., Chéreau, C., Kerdine-Römer, S., Allanore, Y. \& Batteux, F. (2018). The Nrf2-antioxidant response element signaling pathway controls fibrosis and autoimmunity in scleroderma. Frontiers in Immunology, 9, 1-14. DOI: 10.3389/fimmu. 2018. 01896

Kobayashi, M. \& Yamamoto, M. (2005). Molecular mechanisms activating the Nrf2-Keap1 pathway of antioxidant gene regulation. Antioxidant \& Redox Signaling, 7(3-4), 385-94. DOI: 10.1089/ars.2005.7.385

Kore, A.M., Spencer, G.F. \& Wallig, M.A. (1993). Purifcation of the (methylsulfnyl) alkyl glucosinolate hydrolysis products: 1-isothiocyanato-3-(methylsulfnyl) propane, 1isothiocyanato-4-(methylsulfnyl) butane, 4(methylsulfnyl) butanenitrile, and 5 (methylsulfnyl) pentanenitrile from broccoli and Lesquerella fendleri. Journal of Agricultural and Food Chemistry, 41, 89-95. DOI: 10.1021/jf00025a019

Maheao, K., Morel, F., Langouet, S., Kramer, H., Le Ferrec, E., Ketterer, B. \& Guillouzo, A. (1997). Inhibition of cytochromes P-450 and induction of glutathione S-transferases by sulforaphane in primary human and rat hepatocytes. Cancer Research, 57, 3649-3652.

Michaud, D.S., Spiegelman, D., Clinton, S.K., Rimm, E.B., Willett, W.C. \& Giovannucci, E.L. (1999). Fruit and vegetable intake and incidence of bladder cancer in a male prospective cohort. Journal of the National Cancer Institute, 91, 605613. DOI: 10.1093/jnci/91.7.605

Mithen, R. (2001). Glucosinolates and their degradation products. Advances in Botanical Research, 35, 213-262. DOI: 10.1016/S0065-2296(01)35008-5

Mitsuishi, Y., Motohashi, H. \& Masayuki, Y. (2012). The Keap1-Nrf2 system in cancers: stress response and anabolic metabolism. Frontier Oncology, 2, 1-13. DOI: 10.3389/fonc. 2012.00200

Morel, F., Langouet, S., Maheao, K. \& Guillouzo, A. (1997). The use of primary hepatocyte cultures for the evaluation of chemoprotective agents. Cell Biology and Toxicology, 13, 323-329. DOI: 10.1023/a:1007491525955

Shapiro, T.A., Fahey, J.W., Wade, K.L., Stephenson, K.K. \& Talalay, P. (2001). Chemoprotective glucosinolates and isothiocyanates of broccoli sprouts: metabolism and excretion in humans. Cancer Epidemiology Biomarkers, 10, 501-508.

Steinmetz, K.A. \& Potter, J.D. (1991). Vegetables, fruit and cancer. I. Epidemiology. Cancer Cause Control, 2, 325-357.

Talalay, P., Dinkova-Kostova, A.T. \& Holtzclaw, W.D. (2003). Importance of phase 2 gene regulation in protection against electrophile and reactive oxygen toxicity and carcinogenesis. Advance in Enzyme Regulation, 43, 121-134. DOI: 10.1016/s0065-2571(02)00038-9

Tripathi, M.K. \& Mishra, A.S. (2007). Glucosinolates in animal nutrition: A review. Animal Feed Science and Technology, 132, 1-27. DOI: 10.1016/j.anifeedsci.2006.03.003

Verhoeven, D.T., Goldbohm, R.A., Van Poppel, G., Verhagen, H. \& Brandt, P.A. (1996). Epidemiological studies on brassica vegetables and cancer risk. Cancer Epidemiology Biomarkers, 5, 733-748.

Vig, A.P., Rampal, G., Thind, T.S. \& Arora, S. (2009). Bio-protective effects of glucosinolates-A review. Journal of Food Science and Technology, 42, 1561-1572. DOI: 10.1016/j.lwt.2009.05.023

Yang, L., Palliyaguru, D.L. \& Kenslera, T.W. (2016). Frugal chemoprevention: targeting Nrf2 with foods rich in sulforaphane. Seminers in Oncology, 43, 146-153. DOI: 10.1053/j.seminoncol.2015.09.013

Zhang, C.C.G., Posner, G.H. \& Talalay, P. (1992). Spectroscopic quantitation of organic isothiocyanates by cyclocondensation with vicinal dithiols. Analytical Biochemistry, 205, 100-107. DOI: 10.1016/0003-2697(92)90585-u

Zhang, Y., Kensler, T.W., Cho, C.G., Posner, G.H. \& Talalay, P. (1994). Anticarcinogenic activities of sulforaphane and structurally related synthetic norbornyl isothiocyanates. Proceedings of the National Academy of Sciences USA, 91, 31473150. DOI: 10.1073/pnas.91.8.3147

Zhang, Y., Wade, K., Prestera, T. \& Talalay, P. (1996). Quantitative determination of isothiocyanates, dithiocarbamates, carbon disulfide, and related thiocarbonyl compounds by cyclocondensation with 1,2-benzenedithiol. Analytical Biochemistry, 239, 160-167. DOI: 10.1006/abio.1996.0311 